\title{
Zhuangzi on Friendship and Death
}

\author{
Alexis Elder
}

This is the accepted version of the following article: "Zhuangzi on Friendship and Death", which has been published in final form at https://doi.org/10.1111/sjp.12086.

\begin{abstract}
Zhuangzi suggests that death is a transformation that we commonly and mistakenly think means the end of someone but really just marks a new phase of existence. This metaphysical thesis is presented at several points in the text as an explanation of distinctively Daoist responses to death and loss. Some (such as Wong, 2006) take a Daoist response to death, as presented by Zhuangzi, to indicate a dual perspective on friendship and death. But I argue that the metaphysical view sketched above is consistent with a unified perspective that allows the Daoist to enjoy deep friendships without risking some potential for grief typically associated with strong attachment. However, it limits the Daoist to friendships with those who endorse the same metaphysics. Furthermore, while the grief associated with the death of a friend is somewhat mitigated, the Daoist has reason to mourn even given this thesis.
\end{abstract}

Keywords: Friendship, grief, Zhuangzi, Daoism, values

\section{Word count: 8,058}

At points, Zhuangzi suggests that death is a transformation that we commonly and mistakenly think means the end of someone but really just marks a new phase of existence. ${ }^{1}$ I argue that this thesis allows the Daoist to enjoy deep friendships without the risk of loss typically associated with strong attachment, but limits the Daoist to friendships with those who endorse

\footnotetext{
${ }^{1}$ Romanization in the various translations discussed in this paper have all been converted to Pinyin, for the sake of consistency.
} 
the same metaphysics. Furthermore, though they reject the idea that death is a loss, they still have reason to mourn the death of a friend.

There seems to be tension between leading a tranquil life, and being attached to particular individuals, which opens one up to the possibility of grief. But while Daoist sages seem tranquil, there is more room for attachments such as friendship in Daoism than in many other schools of thought which take tranquility to be a feature of a good life. David Wong (2006) argues that while Daoists resemble Buddhists and Stoics in holding that detachment from the world helps one to avoid being brought down by its troubles, the Daoist has a better story to tell about how such detachment should proceed. The Buddhist and the Stoic both, in different ways, seem to counsel detachment from sorrow by avoiding attachment to people. The Buddha, for example, explains that "Delusion alone ties one person to another" (qtd in Wong 2006: 208). Wong notes that other interpretations of Stoicism and Buddhism are available, but is interested in the prima facie challenge that attachment to mortal people is a source of grief that is incompatible with the best life as described by these traditions.

Some take this to show that a life of detachment like that prescribed by Stoics or Buddhists may not be the best human life, because it precludes attachment to other people, which is intuitively important and valuable. But Wong argues that the Daoist can enjoy close relationships and yet maintain some detachment in the face of death by adopting what he calls "a duality of perspectives" (Wong 2006: 215), sometimes taking the point of view of the universe to mitigate human grief at the death of loved ones, at other times taking the perspective of a human being who enjoys social relations but is subject to loss. From the point of view of the universe, one can see the death of a loved one as part of a larger process, something impossible for the human being, he thinks. Discussing Zhuangzi's reaction to the death of his wife, as described in 
Chapter eighteen of the text, Wong writes, "As a small part of the whole, he is a man, and as a man, he must feel the loss of his wife and sob over her death, but as a man with intellect and imagination capable of embracing the whole, he can come to accept her death, his felt loss, and also continue to embrace his wife as part of the whole" (Wong 2006: 214). This portrays the Daoist friend or spouse as divided between two perspectives: that of a particular human being, and that of the universe.

There is a different interpretation of Zhuangzi's writings on death and friendship, however, which preserves friendship and tranquility without positing such a divide in perspective. And while Wong draws almost exclusively on a story from chapter eighteen, one of the "outer" chapters to support his interpretation, a number of stories in the so-called "inner" chapters, bear on the issue at hand. Because the inner chapters are plausibly attributable to Zhuangzi, while the outer chapters were likely contributed by later Daoist disciples and followers, evidence from the inner chapters is especially important in shedding light on Zhuangzi's philosophy (Graham 1979). In the inner chapters at several points, death is discussed in connection with friendship in a way which suggests that a tranquil response to the death of a loved one is possible within the personal perspective. I submit that the Daoist friend reconciles herself to the deaths of both herself and her loved ones by embracing mortality as a quality of the people she is attached to, including herself, within a single perspective, rather than dividing herself between dual perspectives.

On Wong's two-perspective view, the Stoics and the Buddhists have it roughly right; from an unsupplemented personal perspective, devastating grief at the death of loved ones is inevitable. A tranquil life is thus to that extent incompatible with attachment. Only by locating one's personal attachments within the vastness of universe, and assuming its perspective, can one 
come to terms with death in a way that allows for some measure of tranquility and some resilience in the face of death.

However, an alternative interpretation of Zhuangzi is available, one which locates the Daoist response to death within the personal and human perspective, and thus offers a more robust alternative to the Stoic and the Buddhist position on attachment and grief.

This interpretation is suggested by several passages from the inner chapters where death does not disturb tranquility even within the perspective that accommodates friendship. These passages indicate that death is merely a change and not a loss, and so is not grounds for the kind of grief that seems called for when one loses something of value. This alternative interpretation makes better sense of these stories from the inner chapters than does Wong's, and offers a genuine alternative account of friendship, attachment and death that leaves the Daoist in a substantially better position relative to the Buddhist and the Stoic.

On this view, Daoists value people as creatures who inevitably "transform" in death, rather than attaching to only certain qualities and stages of a person, and pretending that these qualities exhaust the individual. The Daoist seems open to the possibility that objects may undergo great change, including dispersal of their parts, without ceasing to exist. Several passages develop the idea that focusing on the presence or absence of a few qualities can mislead us into thinking something has ceased to be and leading us to mourn its loss. The clearer-sighted observer, however, would see that there has been a change or a transformation, without thereby concluding that the object has disappeared. To the Daoist, this ends up being more than just an abstract theoretical claim. It is taken to have significant pragmatic import, and underwrites much of the Daoist ethos. This metaphysics, radical and unconventional, simultaneously sets them 
apart from society while grounding deep friendships between those who share their worldview and values (Blakeley 2008).

This position seems available to Daoists because they embrace the possibility of radical transformations: consider, for example, the story of a fish that changes into a bird which opens the first chapter of Zhuangzi. It would be less appealing to those whose philosophical approaches are characterized by a commitment to producing an ontology that models our ordinary beliefs about persistence and extinction conditions. This makes a position like the one I propose more plausible for the Daoist than for many other schools of thought. By taking Zhuangzi's story of the Four Friends at face value as literally giving a Daoist account of friendship, death and grief, we end up with a picture of attachment that seems consistent with the text at several important points.

Valuing Friends for What They Are

In two stories from the inner chapters, beliefs about mortality form the foundation of several friendships among Daoists. Making this the basis of a friendship would be somewhat mysterious on Wong's account. This is not meant to be a devastating objection to his view, as it is not inconsistent with his view that friends form friendships on the basis of this sort of shared belief. However, a theory of Daoist relationships which could incorporate the shared beliefs as part of an account of how the Daoists respond to death would be at a relative advantage, because in the stories, these particular shared beliefs seem central to the friends' responses to deaths of loved ones. On the two-perspectives account, accepting mortality as natural ebb and flow requires identifying with the universe as a whole and thus, Wong thinks, departing from the perspective of a human being It is therefore not clear why Daoists should find it important to 
befriend people who share one's beliefs about death. From the personal perspective, in which friendships take place, the death of a loved one is, according to the two-perspectives view, roughly as we usually take it to be: a devastating loss. However, if accepting death as change rather than loss is compatible with friendship within a single perspective, then agreement on this metaphysical thesis would naturally have import to Daoists. Its role in friendship could be an extension of the idea that the Daoist as person is better off for being clear on the nature of human beings, and valuing people for who and what they are. And this is what we find in at least two stories about friendship and death.

The first story is found in chapter six. Four men, in the course of talking together, raise the question, "Which of us is able to think of nothingness as the head, of life as the spine, of death as the rump? Which of us knows that the living and the dead, the surviving and the lost, are all one body? He shall be my friend." (Graham 2001: 87) At this question, "The four men looked at each other," we are told, "and smiled, and none was reluctant in his heart. So they all became friends." (Graham 2001: 88)

Blakeley (2008) argues that this serves as their friendship's foundation because it showed they shared the same values. When, in answer to the question, the men confirm (non-verbally, but with smiles indicating their emotional states) that they have the same values, they proceed to become friends. This grounds what Blakeley characterizes as a "relationship based on a particular perspective (lifeworld, form of life, worldview, semantic field, dispositional deportment) and its values." (Blakeley 2008: 329) As the friends' story proceeds, these shared values and shared perspective on death allow them to help each other out at times when living with their values proves difficult, or conflicts with society. 
For example, in one scene, $\mathrm{Si}$ visits $\mathrm{Yu}$ when $\mathrm{Yu}$ is ill. When asked how he fares, $\mathrm{Yu}$ exclaims, "the maker of things is turning me into this crumpled thing. He hunches me and sticks out my back... my chin hides down in my navel, my shoulders are higher than my crown..." (Graham 2001: 88) He describes aging as transformation, and as the conversation continues, takes death to be just another transformation like that which he is currently undergoing.

The two discuss his attitude toward the changes he is going through and will soon undergo. "Do you hate it?" asks Si, referring to these changes. "No, why should I hate it?" responds Yu. (Graham 2001: 88) He proceeds to consider all the different things he will become as his transformation proceeds (especially after he is dead), and all the different things he will go on to become as bits of his body disperse and get incorporated into new things:

If the process continues, perhaps in time he'll transform my left arm into a rooster. In that case I'll keep watch on the night. Or perhaps in time he'll transform my right arm into a crossbow pellet and I'll shoot down an owl for roasting. Or perhaps in time he'll transform my buttocks into cartwheels. Then, with my spirit for a horse, I'll climb up and go for a ride. What need will I have for a carriage ever again? (Watson 2003: 80-81)

Several metaphysical ideas are implied in this unusual exchange: First, Yu identifies himself with his body. He thinks that he will be the things into which his body is transformed. Secondly, in order for him to be these things, he must take himself to persist beyond the dispersal of his body's parts. We normally take dispersal of parts to mark the end of an object, but he seems to characterize this as a mere change: he transitions from coherent to dispersed object. Finally, Yu says the changes are normal and not to be resisted: "to get life is to be on time and to lose it is to be on course; be content with the time and settled on the course, and sadness and joy cannot find a way in." (Graham 2001: 88) For Yu to be tranquil and satisfied with his fate he must accept who and what he is, and value himself for being exactly that. 


\section{Helping a Friend Transform}

As the story continues, we find that this account of death as transformation also gets offered as advice from one friend to another. When Lai, another of the four friends, falls ill, his friend $\mathrm{Li}$ visits, and helps him to maintain his composure even in the face of external pressures and his own imminent death. As Lai "lay panting on the verge of death," we are told, his "wife and children stood in a circle bewailing him". Out of concern for his friend, Li sends the distressed family from the room: "Shoo! Out of the way! ... Don't startle him while he transforms." (Graham 2001: 88) While the Daoist sage is often portrayed as avoiding action and refraining from telling people what to do, here Li steps in and takes charge of the situation in order to help his friend out. Even for the Daoist, friendship seems to license involvement in the world if it aids a friend in need.

Once alone, he offers Lai comfort in roughly the same way that $\mathrm{Yu}$ came to terms with his own death: "Wonderful, the process which fashions and transforms us! What is it going to turn you into, in what direction will it use you to go? Will it make you into a rat's liver? Or a fly's leg?" (Graham 2001: 88) And as Yu did, Li describes life and death as inevitable stages of the same process, and, he elaborates, valuing the process at one stage gives him reason to value the next: "That hugest of clumps of soil loaded me with a body, had me toiling through a life, eased me with old age, rests me with death: therefore that I found it good to live is the very reason why I find it good to die.” (Graham 2001: 88) Life and death are both natural stages of a human being, and if we value a person's life, he reasons, we should likewise value their death. This stands in contrast to the idea that valuing a person leads inevitably to grief at their death.

For a person to value life but resist death would be a perversion of our very nature, he goes on. "If today a master swordsmith were smelting metal, and the metal should jump up and 
say 'I insist on being made into an Excalibur', the swordsmith would surely think it metal with a curse on it." (Graham 2001: 88) Likewise, the person who tried to direct the maker of things about what sort of thing he should be made into (or maintained as) would be defective.

This indicates a natural role for the Daoists' agreement on metaphysics as part of their friendship. In the context of the story, these words are presented as comfort to Lai, and provide him support in sticking to his values in the face of death and the wailing of his family. Because agreement on metaphysics formed the basis of the friendship, Li can then step in and help, both by standing up to Lai's family, and by offering moral support in the form of this strange Daoist pep talk. "As friends care for one another," explains Blakeley, "their caring is determined by their understanding of how to care." (Blakeley 2008: 324) A kind of honesty takes center stage in this version of care: they seem to think that one ought to be cognizant of the nature of what one values, and value all of it, not pick and choose, clinging to some parts at the expense of others.

One might worry that this somewhat strange belief that death is a change and not a loss, especially combined with the Daoists' explicit rejection of one single correct way to divide up the world, would only alleviate grief at the death of a friend by making it somewhat irrational for someone to value a person to begin with. Without rules indicating when an object goes out of existence, they are open to the possibility of objects with widely dispersed parts, so why not just as well value some arbitrary collection of bits of other objects? But I do not think the Daoists are committed to this conclusion, because they reason about how value should be extended to later stages of an object, not about which objects we can or should value to begin with. Daoists can come to value people for all the usual sorts of reasons we come to care for our friends: shared interests and values, compatible sense of humor and personality, and so forth. Their metaphysical beliefs become salient at times like death because, given that they already value their friends, 
their metaphysics suggest that the object of value is not gone, only changed, and that such change is part of the normal course of events. Like metal being reshaped, their friends have changed form, and because they value their friends, they value their friends in these new forms: As Lai puts it, "that I found it good to live is the very reason why I find it good to die." (Graham 2001: 88) A metaphysical perspective that takes some of the sting out of death is then a part of the perspective where we find friendship, and does not stand in need of supplementation, as on the two-perspectives view.

One might object, here, that it would not be clear why it would be plausible to suppose that people continue to value their friends, when the original qualities on which the friendship was initiated have disappeared. But this is in fact paradigmatic of friendship, and not an odd or obscure feature of Daoist friendship in particular. Friendships are frequently praised for their longevity, and good friends value each other as they grow and change, as circumstances shift, and as interests, hobbies, careers, and family roles change, sometimes quite radically. You and I might become friends initially because we are next-door neighbors, because we like the same music, or because we are taking the same college course. But these qualities can change and yet the friendship persist. Friendships may persist through periods of depression, illness, and vastly different life stages. The Daoists, then, seem to be merely extending this ordinary (and intuitively important) feature of friendship in continuing to value their friends through what they take to be transformations and changes, rather than coming up with a bizarre or ad hoc response to death in an attempt to mitigate grief.

Although it might still seem odd to think that a dead person still exists, even after being scattered throughout a multitude of diverse forms, and thus still capable of being valued, there are theoretical advantages that may make it worth the cost. Alternative interpretations of the Four 
Friends passage, perhaps that following the friends' death, what one really values is the universe, which contains the parts of the dead friend, do not adequately explain the partiality characteristic of friendship. If friendship with one's living friends is merely derivative of one's valuing of the universe as a whole, it seems to lack the partiality characteristic of friendship, where we take our friends to be especially valuable. But if one first values the friend, then comes to value the whole universe after the friend dies, this seems to leave too much unexplained. Why think that the friend's death (and, via dispersal of parts, incorporation into other objects throughout the universe) gives one reason to value the universe as a whole, when the friend was equally a part of the universe while alive? It would be preferable to consistently explain why one cares especially for this friend, this part of the whole, and connect it appropriately to the friends' responses to death. The account I propose says that attachment to the friend (that very part) in new forms follows from attachment to the friend in the form in which friends first establish their friendship, as an extension of the loyalty and valuing friends through various changes and stages that already seems salient to friendship. Taking the Four Friends account at face value, rather than metaphorically, allows us to do this.

\section{Forgetfulness as Friendship?}

Another story about friendship and death follows immediately on the preceding passage, and likewise begins with a mutual affirmation of values: together.

The three men, Master Sanghu, Meng Zifan and Master Qinzhang, were talking

'Which of us can be with when there is no being with, be for where there is no being for? Which of us are able to climb the sky and roam the mists and go whirling into the infinite, living forgetful of each other for ever and ever?'

The three men looked at each other and smiled, and none was reluctant in his heart. So they became friends. (Graham 2001: 89) 
The previous passage began with an agreement on metaphysics amongst living friends who eventually faced death. Despite the initial appearance of a disanalogy between that story and this one, I conclude that they are both best read as expressing the same underlying theory of death, friendship and mourning. In this tale, I conclude that a shared belief about death eventually motivates the surviving friends' response to their friend's death.

Wholehearted ability to be "forgetful of each other for ever and ever" seems an odd basis for a friendship; in fact, it seems downright paradoxical (doubtless part of the intention of the story was to draw this out). In this, it differs from the previously discussed story, where friends based their friendship on a shared belief, rather than a rejection of belief, or commitment to forgetfulness. But I think we should not read this part of the story literally. It would not be consistent with the stories told about Daoist friendship to think friends genuinely forget about each other. They are portrayed as thoughtful and considerate, visiting each other when sick, standing up to each other's families, and also assisting in more ordinary ways; later in the chapter, for example, we encounter someone who worries about a friend when the weather is especially unpleasant, and so cooks up and brings him some dinner.

Instead, we can interpret the "forgetfulness" as a rejection of many of our standard beliefs and values, while maintaining that these friends believe other things about the world, such as the metaphysical view explicitly endorsed in the previous story (and with which it shares significant structural features in its setup: in both stories people propose a commitment, everyone agrees to it and expresses their emotional endorsement with smiles, and a friendship is thus established). It seems plausible to suppose that in this story, their emphasis on forgetting is something of a rhetorical shock tactic, emphasizing that their commitment to each other is not supposed to motivate attachment to one phase of this person's existence at the expense of the rest, as one 
would expect if they subscribed to a more conventional metaphysics. This is supported by the way forgetfulness is handled in what follows. One of the friends eventually dies, and Kongzi sends a disciple to mourn his passing. The disciple is horrified to discover the living friends singing together, one "plaiting frames for silkworms, the other strumming a zither" while their friend lies dead at their feet. The two living friends, however, are not portrayed as forgetting their friend: in fact, they are singing about his passing. "Hey-ho, Sanghu! / You've gone back to being what one truly is, / But we go on being human, O!" (Graham 2001: 89) The shocked disciple asks if what they are doing is "in accordance with the rites," at which the friends "exchanged glances and smiled. 'What does he know about the meaning of the rites?'” (Graham 2001: 89)

Kongzi, when he hears about this, does not criticize them for failing to follow the rites. Instead, he characterizes himself as "the sort that roams within the guidelines" while they are, he says, "the sort that roams beyond the guidelines". He is therefore not qualified to comment on them, he explains, because "Beyond and within have nothing in common". He concludes that sending an emissary from within the guidelines was "stupid on my part" (Graham 2001: 89).

The Daoists, the character Kongzi claims, "think of life as an obstinate wart or a dangling wen, of death as bursting the boil or letting the pus." (Graham 2001: 89) But Kongzi seems to be portrayed as missing the point, since the reports by Daoists contemplating their own or their friends' deaths indicate that it is because they value life, and life and death are part of the same process, that death is not to be shunned or feared. Death is not a relief or a blessing, and therefore valuable because it offers relief from life, but just another part of the same thing one already values. But the theme of forgetting is raised again: the Daoists are "Self-forgetful right down to the liver and the gall, leaving behind their own ears and eyes" says Kongzi. (Graham 
2001: 89) Attitudes toward friends (who have explicitly agreed to live "forgetful of each other for ever and ever") are paralleled in attitudes toward self (since they are "self-forgetful"), just as in the last passage, one dying man's comments about his own impending "transformation" are repeated as words of comfort or advice from one friend to another. Kongzi seems to be missing something in calling this "forgetfulness", but lack of concern for conventional cares is evident both in their attitudes towards their friends and themselves. This, however, does not yield indifference to the friend's passing, even given their unconventional beliefs about death: they mark the occasion by singing about the change their friend has gone through, and noting the differences between the sort of thing he is now, and the sorts of things they currently are.

If Daoists were really expected to forget themselves, this might seem consistent with the idea that in dealing with death they adopt the point of view of the universe. But the sort of self'forgetfulness' that is portrayed as appropriate to a good Daoist is not one that precludes attachment or friendship: in fact, it is presented as a foundation that allows their particular form of friendship to flourish. Valuing a friend for himself as he is involves valuing his transformation in death, and so preserves a kind of bond amongst the friends. This interpretation is supported by what the friends are doing when Kongzi's pupil encounters them: not forgetting their friend, but celebrating what he has become, and recognizing what they themselves are.

\section{The Importance of Shared Values}

The two stories discussed so far begin with explicit agreements about the nature of life, death, and friendship, and this seems to be no accident. Given the emphasis elsewhere in the text on the foolishness of trying to change people's natures, it seems that the best way for the Daoist to have friends who share her values is to find people who are already wholeheartedly committed 
to these values. In chapter four, for example, Yan He, who has been appointed tutor to the heir apparent of a local duke, seeks counsel on how to proceed with his pupil, and is told quite firmly not to make waves, nor try to shape the heir's character, nor think that, because the heir appears to have improved, he has thereby changed. Yan He is advised to imitate the tiger keeper, who goes to great lengths both to understand and work with tigers' dispositions. This knowledge informs his choices about what to feed them and when, how to handle them, and how to conduct himself around them: thus, we are told, he "has the secret of their angry hearts." (Graham 2001: 72)

The tigers are thus safe for him to be around, but only this knowledge of and respect for their immutable nature keeps him safe: "when they fawn on the man who feeds him it is because he goes along with their dispositions; and so if they get murderous it is because he thwarts their dispositions." (Graham 2001: 72) This is followed up by a story about a man who pampers his beloved horse but is killed when he startles the animal by swatting at a fly. About this last story, the speaker concludes, there was "nothing wrong with the intention but the love did damage. You can't be too careful." (Graham 2001: 72) The do-gooder bent on transforming the characters of those around him seems doomed to failure, succeeding merely in "making a pest of oneself" (Graham 2001: 67).

Were these Daoists to treat those who do not follow the Dao as they do themselves, presumably it would not go well; one can only imagine that someone with a different attitude toward death would not find it reassuring to be told, "you might turn into a rat's liver!" while lying on his deathbed, or appreciate a friend sending his family away. It is only the shared values identified by Blakeley that allow friends to value each other as they value themselves, without the need to "be careful" lest someone turn on you. With such friends, you can trust both 
that your offers of help will not backfire and that your friend will provide you the help you need, in turn. Thus, the metaphysical thesis that death is a transformation and not a loss ends up being central to these Daoists' friendship, although not something they could expect to be able to convince others to adopt.

\section{Interpreting a Challenging Passage}

The account I have sketched allows us to make sense of a somewhat confusing passage in a neighboring chapter, rendering it consistent with stories about friendship and death told elsewhere in the text. In chapter three, we encounter a story about a friend's grief at the death of the Daoist master Lao Dan. Qin Shi, we are told, "went in to mourn him, wailed three times, and came out." This apparently disturbed a disciple, who asked Qin Shi, “Were you not the Master's friend?" "I was," replies Qin Shi. “Then is it decent to mourn him like this?” asks the disciple. Qin Shi replies in the affirmative. Graham's translation has him explain that "I used to think of him as the man, but now he is not." (Graham 2001: 65) Translations of the text differ on what is said in the last sentence of the story. Graham offers the following as Qin Shi's explanation about why his grieving is so unusual: "If the meaning is confined to what is deemed the 'firewood', as the fire passes on from one piece to the next we do not know it is the "cinders"', Qin Shi tells the disciple (Graham 2001: 65). Watson's translation of this passage runs: "Though the grease burns out of the torch, the fire passes on, and no one knows where it ends." (Watson 2003: 48) Watson notes, in a footnote, that the "first part of this... sentence is scarcely intelligible and there are numerous suggestions on how it should be interpreted or emended." He then lists some of the "other possible interpretations" and credits them: 
"When the fingers complete the work of adding firewood, the fire passes on" (Guo Xiang). "Though the fingers are worn out gathering firewood, the fire passes on" (Yu Yue). "What we can point to are the fagots that have been consumed; but the fire is transmitted elsewhere" (Legge, Fukunaga). (Watson 2003:48)

The translations agree that the explanation involves fire and change, but differ otherwise. The meaning we ascribe to "firewood" is too narrow and so we miss that it becomes cinders; or the fire burned in one place before but now burns in another; or the fire continues to burn although it has consumed one source of fuel. Clearly, what is said is offered as an explanation about responses to death, but what is the explanation supposed to be?

About this passage, Graham has this to say: "The final sentence is obscure. I take it to be using the terminology of disputation. We divide up the changing totality, use names such as 'living' and 'firewood' to detach the partial and temporary, and then suppose that death and burning bring them to an end, forgetting that they are the same thing as what in the next phase in the endless process of transformation will be named 'dead' and 'cinders'.” (Graham 2001: 65) Even, however, if one is not satisfied by his translation of the passage in question, note the parallels between the various alternatives. In each version, we are left with the sense that while the substantial change involved leads most to react to death as a loss, something continues on after death. This seems to explain how different people with different perspectives react to the death of a loved one, and the fact that something continues is supposed to mitigate the Daoist mourner's grief.

Wong suggests that this passage be understood as expressing Qin Shi's “necessary duality of perspective," between "a conscious and self-aware part of the whole that can perceive the eventual extinction of self and those it loves" and that which can "through its intellect and imaginative capacities for identification with the whole ... come to embrace the ceaseless change and the whole as a home that enfolds the small” (Wong 2006: 215). But I argue that for Qin Shi, 
coming to grips with the death of his friend is better seen as his appreciating another step in the natural progression of his friend, and so part of a single, relatively complete perspective. In each of the varied translations of the passage, we find the idea that changes like death do not mark something's end, but rather are transformations. And in all the translations surveyed above, accepting such transformation as natural is linked with appropriate emotional response to death. Qin Shi explains that the conventional sort of grief is out of place and not the reaction of a sage because "In coming when he did, the Master was on time; in departing when he did, the Master was on course. Be content with the time and settled on the course, and sadness and joy cannot find a way in." (Graham 2001: 65)

While Wong says of this story that "the thrust of the passage seems to suggest extirpation [of emotional attachment]" (Wong 2006: 215), possibly down gradable to "acceptance of sorrow and grief as natural reactions to extinction" (Wong 2006:215-16), I suggest a different interpretation may be in order. According to Qin Shi, Lao Dan has merely changed, not disappeared, as the discussion about fire and wood seems to suggest, and so excessive mourning would be out of place.

A few things are noteworthy about this passage. First, as Wong notes (2006: 215), it is significant that Qin Shi does wail at the loss of his friend, albeit briefly. He seems to accept Lao Dan's transformation with equanimity, but this does not prevent mourning altogether. Sadness might not stay for long, but it briefly finds a way in, a point which requires explanation. In Wong's interpretation, his grief ceases when his perspective (and thereby his judgments) change, as he accepts his sorrow as a natural reaction, from the perspective of the universe. Something like this interpretation is also found in Watson's translation of the passage: "At first I took him for a real man, but now I know he wasn't." (Watson 2003: 47) From the perspective of the 
human being, there has been death and loss. Then his perspective changes, and he ceases to grieve. But my theory does not appeal to a change in Qin Shi's judgment to explain his reaction. He may think valuing Lao Dan ultimately required him to accept his mortality as part of what he was. Qin Shi, despite being a good Daoist who accepts even the death of a friend with shocking (to others) composure, freely admits that he has friends, but his attachment does not drive him to mourn conventionally. The mourners who are still wailing inside, he says, "hide from heaven and turn away from what we truly are," and this interferes with the proper valuing of Lao Dan: when we turn away from what we are, we "forget the gift that we received." (Graham 2001: 65) To fail to embrace this aspect of a friend is, apparently, to disregard something important about the very thing we supposedly value. This would be consistent with the stories discussed earlier from the sixth chapter, which emphasize that valuing people when they are alive gives us reason to find death good as well. His brief mourning, however, would still be appropriate given this great change, as it means that he will no longer be able to interact with his friend as they used to; his mourning would be a reaction to change, not loss. Zhuangzi would then be using a story about the death of a friend to emphasize the importance of owning up to the nature of what we love, rather than pretending it is something else, while recognizing the impact great changes can have on us.

\section{Transformation as Occasion for Mourning}

My interpretation of the Daoist's approach is that the death of a friend cannot properly be called a loss of the valued individual, because the object of value (the person) is still there, even though no longer in the same form, and possibly dispersed over many forms (the haunches of a horse, a crossbow, a bug's leg, a rat's liver, and so forth). Because they hold this belief about 
death, their reactions strike many as strange. Hence the confusion we see in Kongzi's disciple who encounters the friends singing over a corpse, and another disciple's reaction to Qin Shi's response to his master's death. But their shared beliefs about and attitudes toward about death help ground their friendships with each other. As shown both by the stories about the friends visiting each other's sickbeds, and the person who brings a friend dinner on a rainy day, they must share a conception of what it is to care that satisfies all concerned. This does not always dictate radical divergence from normal interactions amongst friends. Often, I imagine they interact much as friends normally do: talking, visiting, sharing meals, and so forth. Their reactions to death, however, are unusual on several fronts. First, the friend's death is taken as something to be expected and even valued. Given that they care about their friends, they consider it foolish to fear or hate this transformation, because it is characteristic of the friend they value.

Furthermore, the occasion of dispersal and great change is, or can be, cause for curiosity. This is evident from their conversations in which they speculate about all the things they will become, following their deaths. This gives the friends, as Daoists, special reason to be interested in their friends' deaths, to observe, support, and participate in this process.

At the same time, death is not merely an occasion for curiosity and observation. Even Daoists grieve at the death of friends, although they accept these changes as inevitable. Even given their belief that death is transformation, it can give reason for some sadness. The friend has transformed into something that can no longer participate in the shared activities formerly characteristic of the friendship. When one's friend has died, they can no longer share conversations, or bring each other soup, or stand up for each other, or sing together. In some ways, this seems analogous to the sort of grief appropriate for a friendship that ends when someone moves away. One may appreciate that this is a natural and expected development for 
the friend one cares for, but it still means that the active portion of the friendship, the interactions and exchanges, are over and done with. The interactions and sustained patterns of care that Daoists participate in are diminished once friends can no longer reciprocally care for and visit with each other. They value what their friends have become, but the changes they have undergone mean they are no longer interactive, no longer reciprocally caring.

The Daoist friends in the stories related here seem to be quite clear that they do not lose their friends: they are still around, but in changed form. And this change is not in itself a bad thing; it is not to be resisted, nor dreaded (consider the parable about the foolishness of a metal that demands to be made into Excalibur). But it still seems to call for a kind of grief, expressed by the (brief) wailing of surviving friends, and the song friends sing over a corpse. Death seems to be the end of a partnership, and the fact that the friends are committed to the thesis that life and death are part of the same thread, or more strongly, that death is (only?) a transformation, does not mitigate this. And this might seem sufficient to justify some sadness. Even friends' moving away is a bittersweet occasion at best, and more so when the change involved (as in death) is clearly irreversible: they will never again be able to interact as friends.

Shared acceptance of the metaphysical thesis that death is a transformation rather than a loss allows the Daoist to reap the benefits of friendship and to value friends for exactly what they are, confident that she in turn will be valued (accurately) in the same way. This provides the support and camaraderie of friendship and friends, who visit with you, talk together with you about the issues you confront, and help you stand up to social pressures and expectations that run counter to your values, and simultaneously avoids some of the suffering and grief ordinarily associated with attachment. But sadness is not completely averted even given this alternative conception of death. 


\section{Making Death Personal}

The unified point of view I describe is personal throughout because it takes the Daoist approach to death of loved ones to be governed by an insight into what the Daoist values. What one values is not lost; friends still care for their dead friends as they transform and participate in the process of change (and become bugs' legs, cart wheels, roosters, and so on). We can then see why they think conventional grief in the face of death is somewhat misguided.

They take an appropriate attitude toward death to be involved in accurately valuing the thing one cares about: valuing it as something which transforms. This makes their reaction to death intensely personal throughout, rather than drawing on the somewhat impersonal perspective of the universe suggested by the two-perspectives view. However, even given the belief that the friend is not lost, the end of the friendship as a reciprocal interaction among individuals who share important values is still an occasion for mourning.

My account allows deep friendship to be of a piece with friends' mourning in reaction to death, without threatening overall tranquility, and also explains the activities and values of the friendships described in the inner chapters of Zhuangzi. Therefore, it is both more consistent with the text, and better accomplishes the goal Wong sets out: to show how one can maintain equanimity in the face of death and yet still enjoy attachment and friendship. Finally, it shows that even if one does not take death to be a loss, one still may have cause to mourn, not because one loses a friend but because one loses a friendship.

\section{Conclusion}


This says something about the nature of grief and the way it relates to attachment and friendship. Whether one takes two perspectives on death and friendship or one, we cannot seem to escape grief completely, and, if the Daoist position on friendship and death that I have argued for is correct, then it turns out that what we think about the goodness or badness of death, and whether it marks the end of an object, or merely a transformation, is not sufficient to account for grief at the death of a friend. If, as seems likely, friendship involves interaction and shared values among like-minded individuals, then the death of a friend means the end of this friendship, even given an unconventional account of death, and this itself seems cause for mourning. This seems to show that grief and mourning are not, as one might think, simply about the loss of a loved one, because the friendship itself seems to be valued above and beyond the friend. People mourn even when they take the friend to still exist. While this might seem explicable purely as a matter of selfish concerns (my friend's death means she will not be able to take care of me, talk with me, fend off my family for me, and so forth), I am not sure that this is the case, especially as an account of what motivates the Daoist sages to mourn. Friendship seems to be something they take to be valuable in its own right, not merely as an instrumental means to their own care, nor yet simply a matter of valuing the friend as individual. Once a friend dies, there is no longer reciprocal caring between friends, but one friend may still care deeply for the other (as Li says about himself, "that I found it good to live is the very reason why I find it good to die" (Graham 2001: 88) and the same reasoning would seem to be applicable to one's friends as oneself: the reasons they find it good that their friends live is the reason they find it good to die).

It is not at all obvious that the metaphysics they endorse is plausible, and given their resistance to proselytizing, it is unsurprising that their presentation of their metaphysical beliefs should strike many as strange and counter-intuitive. This might at first blush seem to limit the 
lessons to be drawn from examining their position. But regardless of whether one finds their approach appealing, I think there is something to be learned: we can either take the preceding to show that a perspective on death that says death is not bad will not sufficiently address grief, or that, without such a strange approach to death, we are left with exactly the problem we started out with: tranquility and attachment are incompatible. We can mitigate this by stepping outside ourselves and identifying with the universe (as we see in Wong's two-perspectives approach), or we can give up on attachment (as the Buddha seems to exhort), or we can give up on death as a loss (as I argue that the Daoists do), but each of these approaches is unsatisfactory in various ways. Adopting the point of view of the universe seems to imply that the human perspective is badly incomplete, while giving up on attachment rules out an important good altogether. Giving up on the idea that death is a loss does not fully protect us from grief, and comes at a high theoretical cost in terms of plausibility, and also alienates us from those who do not share our beliefs.

On the other hand, there seems to be something right about the thought that valuing our loved ones includes accepting their capacity for transformation and changes of all sorts, including those which render continued interaction impossible. While such a belief does not protect us from grief entirely, is seems to be the most honest way to value our friends, and the grief one is subject to on such an account may still be compatible with a relatively tranquil ideal of life, by finding a role for accepting friends' changes in the context of valuing them as creatures capable of great change. This would count as a point in favor of the interpretation I have presented here.

\section{Bibliography}


Donald N. Blakeley, 'Hearts in agreement: Zhuangzi on Dao adept friendship', Philosophy East \& West 58(2008), pp. 318-336.

A. C. Graham, 'How Much of Chuang-Tzu Did Chuang-Tzu Write?' in Studies in Chinese Philosophy and Philosophical Literature, ed. A.C. Graham. (Albany: State University of New York Press, 1990)

David B. Wong, 'The Meaning of Detachment in Daoism, Buddhism, and Stoicism', Dao: A Journal of Comparative Philosophy 5 (2006), pp. 207-219.

Zhuangzi, Zhuangzi: Basic Writings, trans. Burton Watson. (New York: Columbia University Press, 2003)

---, Chuang-Tzu: The Inner Chapters, trans. A.C. Graham. (Indianapolis, Indiana: Hackett, 2001) 